\title{
A Study on the Strategy of Developing New Agricultural Management Business Entity in North-west Poverty-stricken Area
}

\author{
Quanlu Lin ${ }^{\mathrm{a},}{ }^{*}$, Jianxiong Zhu \\ School of Economics and Management, Lanzhou University of Technology, Lanzhou, China \\ a 18262393156@163.com
}

\begin{abstract}
Keywords: Three most, backward and weakest, relevant countermeasures.
\end{abstract}
\begin{abstract}
Agriculture is the first industry in China, the development of agriculture plays an important role in economic and social development. New agricultural management business entity is rooted in agriculture. As an important support for precision poverty alleviation, it is of great significance to build a well-off society in an all-round way. The north-west poverty-stricken area is a typical "three most" (the poorest, most backward and weakest) area in China, which belongs to the ecologically fragile, harsh living conditions. There are still many problems in the development process of the agricultural management business entity which is based on large farming households and family farms, supported by the farmers' professional cooperatives and the agricultural leading enterprises. In this paper, the agricultural management business entity in the north-west poverty-stricken area is the object of study, we analyze the current situation and the existing problems of it, and put forward the relevant countermeasures.
\end{abstract}

\section{Introduction}

The agricultural management business entity of the new agricultural management system in China mainly include the big farmers breeding large farming households, family farms, farmers' professional cooperatives and leading agricultural enterprises, the big farmers breeding large farming households generally refer to specialized production around a certain kind of agricultural products. From the scale of planting and breeding, it is obviously larger than that of the general farmers. It has certain scale of production and professional breeding technology, and the breeding area has reached certain requirements [1]. The main labor force of family farms is family members, they are mainly engaged in intensification, commercialized agricultural production and operation, and agricultural income as the main source of family income [2]. Farmer professional cooperatives refers to a mutual production and operation organization based on the principle of voluntary joint and democratic management on the basis of household contract management, the use of similar agricultural producers, producers or service providers[3]. Agricultural leading enterprises are mainly processed or circulated by agricultural products, through ordering contracts, making cooperation and other ways to drive farmers into the market, doing the production and processing of agricultural products of unification of trade workers and peasants [4].

As early as 2001, "China's Rural Poverty Alleviation and Development" White Paper" put forward the cooperation of enterprises and farmers to establish the production and processing base of agricultural products [5]. The "Outline of China Rural Poverty Alleviation and Development (2011-2020) " had proposed to solve the problem of food and clothing in some concentrated areas of poverty[6], the national "13th Five-Year" program and the nineteen major report of the communist party of China put forward to build a modern agricultural management system and cultivate new aricultural management business entity, the north-west poverty-stricken area is the key area for poverty alleviation, the new agricultural management business entity is rooted in agriculture. It is an important way to adjust the structure of the agricultural industry and an important force for the structural reform of the supply side. 


\section{Regional Definition of North-West Poverty-Stricken Area}

"China Rural Poverty Alleviation and Development Outline (2011-2020)" divides 14 special areas of special difficulty (abbreviated as poverty-stricken area). It mainly includes Liupan mountain area, Qinba mountain area, Longzhong south area and Sanjiang source area, etc, totally 148 counties and districts (the particularity of the southern Xinjiang area is not included in the study of this subject), which belong to the poverty-stricken area of ecological vulnerability, Poor living environment, harsh living conditions. The problems "Three Most" (the poorest, the most backward, and the weakest) are prominent. Liupan mountain area includes 61 counties, such as Gansu, Shaanxi, Ningxia, Qinghai and other provinces and municipalities, Qinba mountain area includes 38 counties, such as Shaanxi, Gansu and other provinces and cities, Four provinces and Tibetan areas includes 42 counties, such as Gansu, Qinghai and other provinces and cities, Lvliang mountain area includes 7 counties in Shaanxi Province, the total area of 1,003,950 square kilometers, the population of 37,623,300 people. Most of the north-west poverty-stricken areas are located in the seismic fault zone and the ecological fragile area, water resources and arable land are far from matched, which is the main battlefield for poverty alleviation in the new phase.

\section{The Present Situation of the Development of the Agricultural Management Business Entity in North-West Poverty-Stricken Area}

The new agricultural management business entity is the key to build specialization, standardization, intensive and socialized agricultural management system in China. It is an important driving force for the transformation from traditional agriculture to modern agriculture [7]. The emergence of new types of agricultural management business entity represented by large farming households, family farms, farmers' professional cooperatives and agricultural leading enterprises, etc, is beneficial to promote the specialization of agricultural production and management activities, the intensification and standardization, and the rapid development of agricultural scale management and agricultural modernization. With the continuous development of urbanization in China, a large number of rural labor force work in cities, the circulation of rural land has been increasing, it provides a development opportunity for the adjustment of the agricultural structure, the agricultural scale management and the cultivation of new agricultural management business entity. However, the construction of new agricultural management system is still in the primary stage, and still faces many problems.

\subsection{The Development Situation of the Large Farming Households}

The number of large farming households is scarce. Because the north-west special areas are mostly located in the earthquake fault zone, the ecological fragile area, the water resources and the plowing land are far from matching, and the construction of agricultural infrastructure is relatively backward, this brings a lot of inconvenience to the agricultural producers. According to the investigation, in Huangzhong County, only 60 large households have been registered, some large farming households hire only 1 2 employees for a year, and also employ only some machinery and a small amount of labor in the busy season.

Small business scale, low economic benefit. Due to the distribution of regional land resources and the requirements of the Household Contract Responsibility System, the land farming resources contracted by farmers are mostly fragmented. While a small number of large households have free arable land, most of the cultivated land is derived mainly through the transfer of relatives and neighborhood relations. The operation of the land are mostly farmers abandoned land, most of the cultivated land is derived mainly through the relationship between relatives and neighbors. There are many problems in these lands, such as remote, inconvenient transportation, small plots and large slope, and the land area is relatively small, it is difficult to reach the economic effect of scale, and the economic benefit is generally low.

Backward breeding technology and insufficient management ability. The farmers in the north-west poverty-stricken areas are less educated, and the cultural base of the farmers is relatively weak. The number of farmers who have mastered a certain agricultural technology and the concept of 
agricultural management are also very few, the management ability of large farming households is limited, and the level of breeding technology is lower than that of the eastern agricultural region. These are also the factors that lead to the stagnant status of the agricultural operation and development of large households in the north-west region.

Lack of funds and financing difficulties. In the north-west special stricken area, the industry is mainly engaged in farming, forestry and animal husbandry, the operating conditions are limited by natural conditions and geographical conditions, and the level of operating income also has greater uncertainty, the income of funds is characterized by a long return cycle and relatively low income, and the flow of funds is unstable and reliable, and financial institutions generally pursue low risks and maximize profits, and are reluctant to lend to large farming households. Therefore, it is difficult for big farmers to obtain financial support from financial institutions.

\subsection{The Development Situation of Family Farms}

The family farm has small scale, many middle links and large transaction cost. The main labor force of family farms is family members. They are small in scale and low in production level, so it is difficult to form intensive agricultural production and operation, besides, there are many middle links in the family production and operation, and the transaction cost is relatively large.

The level of culture is generally low. The cultural level of family farmers in the north-west poverty-stricken area is generally low. By 2015, the level of education in Shaanxi, Gansu, Qinghai and Ningxia was higher than that of other provinces in China. In the population aged 6 and over, the proportion of Shaanxi junior middle school and its below educational level accounts for about $66 \%$, while that of Gansu junior middle school and its below educational level account for $71 \%$, while that of Qinghai junior middle school and its below educational level account for $78 \%$, while that of Ningxia junior middle school and its below educational level account for $70 \%$, this shows the cultural level of farmers is generally low in the north-west poverty-stricken area[8].

The rural labor force is rar. The economy is very backward in the north-west poverty-stricken area. Most of young labors force in the countryside work outside, more old people, women and children stayed in the countryside. The phenomenon of "hollow village" is more serious, most of the rural land is deserted, and left-behind personnel lack of knowledge, they have conservative thought and poor ability to accept new things. But there are hardly any new farmers who are suitable for family farms, and the labor force is rather scarce.

\subsection{The Present Situation of the Development of Farmers' Professional Cooperatives}

The development of farmers' professional cooperatives in the north-west poverty-stricken areas is slow, which is mainly faced with the following status. The phenomenon of agricultural feminization and aging is obvious. Due to the relatively low physical quality and cultural level of the left behind population, there is a shortage of talents for the establishment and development of the farmer cooperatives. The labor force of the agricultural cooperatives is mainly left behind women and the elderly. The phenomenon of agricultural feminization and aging is becoming more and more prominent. Takeing the animal husbandry in Xiji County as an example, the livestock breeding industry of Xiji County focus on beef cattle, sheep breeding, However, due to the lack of human resources in cooperatives, the operation of animal husbandry cooperatives is not ideal, which is far from enough to meet the needs of animal husbandry development, resulting in poor operation efficiency of cooperatives. Besides, agricultural policy support system is not perfect, some local governments have insufficient support for agricultural cooperatives, they failed to implement the state's policies on agriculture benefiting, ignoring the economic problems encountered by agricultural cooperatives in the actual operation process, it is difficult to attract foreign investment in local agricultural cooperatives. In addition, agricultural cooperatives lack agricultural technical guidance in the process of operation.

\subsection{The Present Situation of the Development of the Leading Agricultural Enterprises}

The floating capital of the agricultural leading enterprises is insufficient and the operation is more difficult. Most of the agricultural leading enterprises in the agricultural production and management face insufficient flow of funds, and the slow speed of the circulation, the higher cost of operation. The 
local agricultural leading enterprises are low in scientific and technological content and lack of market competitiveness, most enterprises are generally lack of professional talents, and the ability of independent innovation is not enough. The competition gap between them and the domestic industry leading agricultural enterprises is still large, and the brand effect is relatively small.

\section{The Existing Problems in the Development of Agricultural Management Business Entity in the North-West Poverty-Stricken Area}

\subsection{The Existing Problems in the Development of Large Farming Households}

Large farming household lack of professional breeding technology. In the process of breeding, the traditional backward breeding technology is still used, the speed of breeding technology is slow, and the income of the breeding industry is not high.

Management ability of large farming household is poor. The new type of agricultural management, which is established by the traditional farming and animal husbandry production, occupies a large proportion. However, many local farmers have no knowledge of the fields of intensive processing, sales and circulation, and lack of experience in agricultural management and management, and have more arbitrary in management. No perfect management system and mode of operation have been established, and the connection between employees is not close and not in place.

Large farming household have no financial support and face financing difficulties. The large farmers have limited funds and narrow local financing channels. It is very difficult to obtain loans through the banks. In addition, the national financial subsidies and financial support funds enjoyed by large farming households is rare, which limits the expansion of the scale of their operation.

\subsection{Problems in the Development of Family Farms}

The level of intensive management of family farms is low. Family farms are the main labor force of family members themselves, apart from its own cultivated land, they also get the land through their relatives and neighbors, and the area of their cultivated land is limited. In addition, influenced by factors such as backward productive forces, bad natural conditions and the limited capital strength of family farm operators, the intensive management of farm agriculture in the family farms is generally low.

Farmers' understanding of land property rights is not clear. The rise of production to a certain extent is the primary condition for the formation of family farms. Therefore, rural land needs to be transferred, during the process of land circulation, farmers need to make clear the concept of ownership of land, the right to contract, and the right to operate. However, because of the low level of farmers' culture in the north-west poverty-stricken area, the farmers' cultural level is generally low. The rate of land circulation is low, farmers can only stay in their own land to engage in small-scale production.

The labor productivity is low. Most of the young people go out to work, the majority of the elderly, women and children stay in the countryside, while the labor ability of the elderly and the women is weaker than that of the young adults, they lack the contact with the outside world, have poor ability to learn new things, this also leads to the low labor productivity of family farms, and it is not conducive to the stable and rapid development of family farms.

\subsection{The Problems in the Development of Agricultural Professional Cooperatives}

Farmers' professional cooperatives lack benefit coordination mechanism. Good benefit coordination mechanism can promote the stable and stable development of farmers' professional cooperatives, and it can bring considerable economic benefits to the members of the cooperative. In the north-west poverty-stricken area, some agricultural professional cooperatives do not take the collective interests of the members of the farmers' professional cooperatives into account, and do not make a reasonable profit distribution mechanism. Some agricultural cooperatives and members of the community are only a simple commodity trading relationship and not close contact, some farmers' professional cooperatives only consider the core members' interests of cooperatives, and some 
agricultural cooperatives inhibit farmers' bargaining power and squeeze farmers' agricultural products trading.

Agricultural professional cooperatives are overly dependent on the support and support of the government. Some agricultural professional cooperatives are weak in self-development and are overly dependent on the preferential policies of the state and local governments. According to the investigation, many co-operative leaders say that there is no support policy for the local governments of the country, and it is difficult for agricultural cooperatives to continue to operate.

\subsection{The Problems in the Development of the Leading Agricultural Enterprises}

The phenomenon of non-grain production in agriculture is serious. The benefits of growing cash crops are far greater than grain planting, so, many of the agricultural leading enterprises in the north-west poverty-stricken area chase the economic interests, and plant trees and flowers, vegetables and fruits, and other economic crops on the transferred farmland, or develop sightseeing agriculture and engage in leisure tourism, and engage in leisure tourism. Some will waste land, wait for government land expropriation, and even change the use of land without authorization, and develop small property rights. However, non-grain and nonagricultural chemicals will seriously undermine the foundation of cultivated land protection and food security in China.

Although many agricultural leading enterprises in the north-west poverty-stricken area have integrated the agricultural elements, they often overlook the family management of the upstream agriculture, and use the family management of agriculture to replace the enterprise employment mode, and hire a farmer for a part-time job, but the cost of labor control in the field has been increased, the efficiency of enterprise production has been reduced, resulting the enterprises into the dilemma of development.

Overcapitalization results in an extrude effect. Compared to other agricultural enterprises, the capital strength of the agricultural leading enterprises is the most abundant. With the support of the active encouragement of the local government and the support of the agricultural welfare policy, some agricultural leading enterprises register family farms or cooperatives in the name of their home relatives, besides, many leading agricultural enterprises rely on their own strength to raise lands' rent, disturb the price of the land circulation market, and exclude small and medium-sized business entities who focus on grain and weak capital strength, and squeeze their living space.

\section{Measures for the Development of New Agricultural Management Business Entity in the North-West Poverty-Stricken Area}

\subsection{Measures for the Development of Large Farming Households}

The relevant departments of the local government should actively introduce advanced farming technology in the developed agricultural province. According to the actual situation of local agricultural operation, the traditional breeding technology is combined with the imported breeding technology. In addition, the government should provide professional cultivation technical personnel for large farmers and provide technical guidance for the agricultural management of large farmers.

Local government agencies should establish vocational training institutions for farmers to improve the knowledge and management of large farmers, and provide management consultancy service platform for large farmers, and answer the management problems in the process of agricultural management in time. Large farming households should constantly learn the relevant knowledge of agricultural management, and constantly accumulate management experience and lessons.

Local government agencies should increase financial support and fund support to build a financing service platform. According to the shortage of funds and the difficulties of financing for large farming households, local government departments should increase financial subsidies for agriculture, increase financial support, and set up convenient financing platform for large farmers to expand financing channels for breeding households. 


\subsection{Measures for the Development of Family Farms}

Local government should strengthen policy support. The local government can start to support family farms in the following areas: the first is to give financial subsidies to family farms, and guide and encourage commercial banks and related agricultural insurance companies to establish credit businesses and broaden the financing channels for family farms.; The second is to give family farm appropriate tax incentives to reduce or reduce loan interest rates; The third is to widen the insurance varieties for family farms and reduce the loss of farmers in production and management; and the fourth is to encourage financial institutions to expand the scope of mortgaged goods and give support to land.

Carry out agricultural skills training to farmers and raise the cultural level of farmers, and make clear the concept of ownership of land, the right to contract, and the right to operate, and raise farmers' awareness of land property rights and raise the labor productivity of family farm members.

\subsection{Measures for the Development of Agricultural Cooperatives}

Promote the healthy development of professional cooperatives. On the one hand, local government should increase the construction of infrastructure and information construction for agricultural cooperatives, reduce taxes and increase agricultural financial subsidies, and give support to the training and introduction of talents. On the other hand, the agricultural professional cooperatives should standardize the management, improve the organization and management system of the local agricultural cooperatives, implement the dynamic management of the survival of the fittest, carry out the activities of the demonstration society, and support the excellent agricultural cooperatives [9].

Speed up the improvement of interest coordination mechanism. Agricultural cooperatives must accelerate the improvement of the benefit coordination mechanism, and ensure the economic interests of the members of the cooperative society. Agricultural cooperatives should sign contracts related to agricultural products and other related contracts under the condition of symmetric information, and take account of the equality and reciprocity relations among all stakeholders within the cooperative [10].

Improve the agricultural policy support system and increasing the technical guidance. On the one hand, local tax bureau should give preferential treatment to agricultural taxes, for example, provide rural technologies for exemption from income tax to the farmers' professional cooperatives. On the other hand, local government should encourage farmers' professional cooperatives to increase investment in science and technology and give corresponding policy support. Local governments at all levels and agricultural authorities should actively develop platforms for agricultural cooperatives, and actively set up a platform for the development of agricultural cooperatives, improve the investment and development environment of agricultural cooperatives in the northwest connected areas, and attract and encourage all kinds of business entities to invest in the construction of farmers' cooperatives, to promote the independent operation and development of agricultural cooperatives.

\subsection{Development Measures of Agricultural Leading Enterprises}

Agricultural leading enterprises should adhere to the development concept of "focusing on agriculture, focusing on projects and focusing on attracting investment", they should develop local characteristic agricultural products according to local conditions, actively attract enterprises to participate in agricultural investment activities, comprehensively develop modern agricultural industrial parks, and process three major project carriers.

In order to improve the market competitiveness of the leading agricultural enterprises, the first is to promote the cooperation between the agricultural leading enterprises and the local institutions of higher learning, and constantly improve the technological innovation ability of the enterprises. The second is to increase investment in science and technology to guide agricultural enterprises to increase investment in science and technology, set up R \& D institutions, strengthen the agricultural scientific research institutes and tertiary institutions, introduce foreign advanced technology and equipment, carry out integrated innovation, and cultivate a batch of scientific and technological agricultural leading enterprises with strong market competitiveness. The thrid is to strengthen the enterprise quality supervision, the quality standard system of agricultural products should be set up, the quality 
and the organic agriculture are vigorously developed, and the specialized and standardized production base of agricultural products is built. The fourth is to do security work. Agricultural leading enterprises should strengthen the enterprise safety management efficiency and weightier than Mount Tai "safety consciousness, standardize the operation procedure, implement all relevant safety measures [11].

Pay attention to policy support and strengthen leading enterprises. The first is to guide the leading enterprises to increase their self-investment and set up a large enterprise group. The second is to formulate support policies, Local governments at all levels should formulate preferential policies to support their development, and give financial support in the introduction of new varieties, new technologies, new equipment, new processes, quality management, introduction of high-tech talents and taxation. The third is to conscientiously implement the preferential policies at all levels, intensify the integration of existing policy funds, and focus on supporting the leading enterprises with broad prospects and strong competitiveness, improve the deep processing degree of agricultural products, and improve the comprehensive utilization rate and added value of agricultural and sideline products.

\section{Acknowledgements}

This work was supported by National Social Science Fund Project (14XJY014), I am grateful to my supervisor Lin Quanlun for giving me guidance in the essay writing. In the process of writing, I refer to the articles of these excellent authors, such as Chunping Wang, Chenglin Yang, Dingxiang Wang, Zhaoxin Zhang and so on, I give my sincere thanks to them.

\section{References}

[1]. Chunping Wang, "Several issues concerning the cultivation of a new type of agricultural operation subject," New Agriculture, pp. 7-9, 2013.

[2]. Chenglin Yang, "The study of the Chinese family farm mechanism -- based on the case analysis of "small big households" in the middle of Anhui province," China's Population, Resources and Environment, Oct 2014.

[3]. Dingxiang Wang, Jinpeng Tan, "On the characteristics of modern agriculture and the construction of new agricultural management system," Rural Economy, Sep 2015.

[4]. Zhaoxin Zhang, Hai Zhao, "The dilemma of the new type of agricultural management and the innovation of its institutional mechanism," Regional Economy, Feb 2013.

[5]. "China's Rural Poverty Alleviation and Development " white paper:

[6]. http://www.cpad.gov.cn/art/2006/3/3/art_46_12298.html.

[7]. "Outline of China's Rural Poverty Alleviation and Development":

[8]. http://www.cpad.gov.cn/art/2006/11/20/art_46_12309.html.

[9]. Peng Yuan, Ruijuan Zhang, "Progress, models and suggestions for the construction of new agricultural management system," Jiangxi Social Sciences, pp. 47-53, Oct 10, 2013.

[10]. China Statistical Yearbook: 2016 http: / / www.stats.gov.cn/

[11]. Shengfeng Wang, "The Countermeasures of cultivating new agricultural management subject in Huangzhong county," Social Service, pp. 50-51, Feb 2013.

[12]. Kai Zhang, "The present situation of the development of farmers' professional cooperatives, problems and solutions to them," Academic Exchange, pp. 101-106, 2011.

[13]. Weixin Zheng, "Research on the development of agricultural leading enterprises," Modern Trade and Industry, pp. 23, 2016. 